\title{
openheart Budget impact analysis of PCSK9 inhibitors costs from a community payers' perspective in Apulia, Italy
}

\author{
Natale Daniele Brunetti, ${ }^{1}$ Luisa De Gennaro, ${ }^{2}$ Lucia Tricarico, ${ }^{1}$ \\ Pasquale Caldarola ${ }^{2}$
}

To cite: Brunetti ND, De Gennaro L, Tricarico L, et al. Budget impact analysis of PCSK9 inhibitors costs from a community payers' perspective in Apulia, Italy. Open Heart 2019;6:e01018. doi:10.1136/ openhrt-2019-001018

Received 18 January 2019

Revised 1 July 2019

Accepted 4 July 2019

\section{Check for updates}

(c) Author(s) (or their employer(s)) 2019. Re-use permitted under CC BY-NC. No commercial re-use. See rights and permissions. Published by BMJ.

${ }^{1}$ Università degli Studi di Foggia, Foggia, Italy

${ }^{2}$ Presidio Ospedaliero San Paolo, Bari, Italy

\section{Correspondence to}

Dr Natale Daniele Brunetti; nd. brunetti@unifg.it

\section{ABSTRACT}

Introduction Despite established clinical efficacy of PCSK9 inhibitors (PCSK9i) in reducing cardiovascular events, their cost still represents a big matter of debate. We therefore sought to estimate possible impact of PCSK9i therapy from a community taxpayers' perspective with a budget impact analysis based on data coming from two randomised trials (FOURIER (Further Cardiovascular Outcomes Research with PCSK9 Inhibition in Subjects with Elevated Risk), ODYSSEY OUTCOMES (Evaluation of Cardiovascular Outcomes After an Acute Coronary Syndrome During Treatment With Alirocumab)). Methods The analysis focused on Apulia region, South-Eastern Italy (4 million inhabitants). Costs per cardiovascular event saved were calculated from randomised trials data and annually indexed per Apulia's inhabitants.

Results On the base of actual cost in Apulia, individual costs per saved adverse event ranged from $€ 0.12$ to $€ 0.78$, with just $€ 1$ annually spent per Apulia's inhabitant, 2-8.3 events could be avoided thanks to the use of PCSK9i.

When considering high-risk subgroups (baseline cholesterol levels $>100 \mathrm{mg} / \mathrm{dL}$, multivessel coronary disease), the annual cost per Apulia's inhabitant for one death avoided was more than halved to $€ 0.19$ and the cost for a saved major adverse cardiovascular event was $€ 0.07$. With $€ 1$ annually spent per Apulia's inhabitant, 10.9-15 major adverse cardiovascular events and 5.3 deaths could be saved.

Conclusions When considered from a large taxpayers community perspective, relevant costs per cardiovascular event saved with PCSK9i may turn into very small individual costs per year. The selection of high-risk subgroups may further reduce individual costs.

\section{INTRODUCTION}

The recent introduction of PCSK9 inhibitors (PCSK9i) in the treatment of hypercholesterolaemia, either in primary (familial hypercholesterolaemia $(\mathrm{FH})$ ) or secondary prevention after acute myocardial infarction (MI), radically innovated lipid-lowering therapy. The use of PCSK9i was safe and effective in the whole continuum of hypercholesterolaemia, from statin intolerants ${ }^{1}$ to lipid-lowering

\section{Key questions}

What is already known about this subject?

- PCSK9i are effective in reducing cardiovascular events.

What does this study add?

- PCSK9i may have a positive budget impact analysis profile when considered from large community payers' perspective.

How might this impact on clinical practice?

- In the presence of positive budget impact analysis, the large use of PCSK9i mauy be sustainable for large communities of taxpayers.

naive users, ${ }^{2}$ in addition or in alternative to ezetimibe, ${ }^{3}$ with either low-intensity and high-intensity statins, ${ }^{4}$ in $\mathrm{FH}^{5}{ }^{5}$ The switch to PCSK9i use is a more effective option than statin titration ${ }^{6}$ or switching between statins. Several clinical studies explored the efficacy of both evolocumab ${ }^{7}$ and alirocumab in lowering cholesterol levels down to blood concentrations unattainable with other drug approaches. ${ }^{89}$

Two recent randomised clinical studies finally demonstrated that such massive reduction of cholesterol levels correspond to lower rates of adverse cardiovascular (CV) events and mortality in subjects with CV disease. ${ }^{1011}$ Despite clinical efficacy of PCSK9i in reducing $\mathrm{CV}$ events and cholesterol levels seems well established and endorsed by guidelines, ${ }^{12}$ the cost of PCSK9i still represents, however, a big matter of debate. Cost analyses conducted according to extremely rigorous criteria provided conflicting data on cost-effectiveness of this new class of drugs. ${ }^{13-15}$

However, such 'rigorous' approach to cost-effectiveness analysis does not always encompass the whole spectrum of cost burden of drugs and therapies. Studies such that from Poulsen $e$ al show that, with a pharmacoeconomic analysis considering just the 


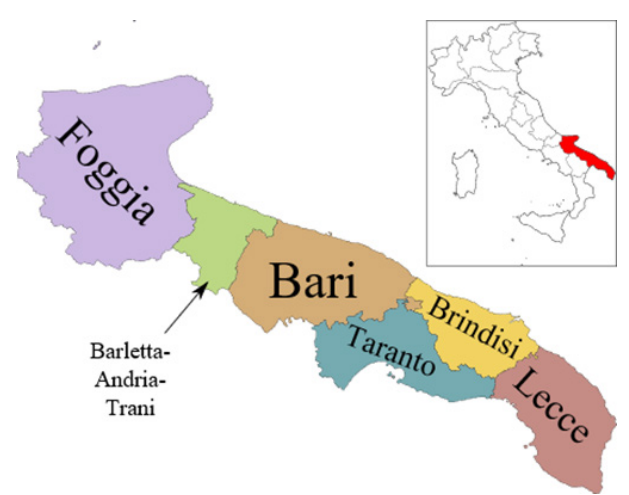

Figure 1 Apulia, South-Eastern Italy, 4 million inhabitants.

cost of a new drug, it is often impossible to appreciate the whole possible positive impact following the introduction of a new treatment; that is the case of direct anticoagulants in the prevention of thromboembolic complications of atrial fibrillation. ${ }^{16}$ When, instead, also individual, municipality and social costs are duly weighted, apparent increased costs may turn into considerable savings.

We therefore sought to estimate possible impact of PCSK9i therapy from a community payers' perspective with a simple budget impact analysis (BIA) based on new data coming from two randomised trials on PCSK9i, recently published: the Further Cardiovascular Outcomes Research with PCSK9 Inhibition in Subjects with Elevated Risk (FOURIER) ${ }^{10}$ and the Evaluation of Cardiovascular Outcomes After an Acute Coronary Syndrome During Treatment With Alirocumab (ODYSSEY OUTCOMES) study. ${ }^{11}$ According to common definitions, BIA should be defined as an economic evaluation conducted according to the budget holders' perspective, with a short time horizon ( $<3$ years) and within a clearly specified setting, where results are expressed as undiscounted cost differences between the new scenario (including the new technology or drug) and the current/reference scenario, taking account of the potential trade-offs in healthcare resources induced by the effectiveness of the new technology/drug, and easy to understand by budget holders ${ }^{17}$; the approach is radically different from a cost-effectiveness analysis.

\section{METHODS}

The cost analysis was based on data from randomised studies on clinical endpoints with evolocumab and alirocumab. ${ }^{10}$ Clinical endpoints considered were death, MI, stroke, major adverse CV events (MACEs, death from CV causes, non-fatal MI, unstable angina requiring hospitalisation, an ischaemia-driven coronary revascularisation procedure or non-fatal ischaemic stroke), or the composite endpoint death, MI, stroke for the ODYSSEY OUTCOMES study, MI, stroke, MACE (CV death, MI, stroke, hospitalisation for unstable angina, coronary revascularisation), the composite endpoint CV death, MI, stroke for the FOURIER study. Data from two randomised studies were used to estimate absolute risk reduction and consequent number needed to treat for each drug and outcome. The follow-up considered was 34 months for the ODYSSEY OUTCOMES study and 26 months for the FOURIER.

The analysis focused on Apulia region, South-Eastern Italy (4063888 inhabitants ${ }^{18}$ (figure 1)). The cost of drugs is locally paid by Regional Public Health Care System for all citizens according to official drug indications when endorsed by local Healthcare Authority. The considered cost for 1-year treatment was currently $€ 4500$, according to present bargain between pharmaceutical companies and Apulia Public Health Care System.

The cost per saved event (annual cost of therapy per number needed to treat) was indexed per 1 year to compare results from studies with different follow-up. Costs per CV event saved were calculated and indexed per Apulia inhabitants to allow a comprehensive evaluation of community costs as in prior analysis. ${ }^{19}$ Data were also presented as individual (per Apulia's inhabitant) cost per saved event and events saved for individual $€ 1$ expense per 1 year.

\section{RESULTS}

On the base of actual cost in Apulia sustained by Regional Public Health Care System for PCSK9i, Apulia's population, clinical efficacy data from randomised clinical studies, different follow-up durations, absolute risk reduction, number needed to treat, esteemed costs per $\mathrm{CV}$ event avoided thanks to alirocumab therapy were $€ 2.1$ millions for one death, $€ 1.3$ for one MI, $€ 3.2$ for one stroke, $€ 0.7$ for one MACE (death from CV causes, non-fatal MI, unstable angina requiring hospitalisation, an ischaemia-driven coronary revascularisation procedure or non-fatal ischaemic stroke) and $€ 0.8$ for one major event (CV death, MI, stroke) (table 1).

However, when costs per saved adverse event were indexed according to Apulia's population (and an ideal taxpayers' community), the individual annual cost per CV event avoided thanks to alirocumab therapy was $€ 0.51$ for one all-cause death, $€ 0.31$ for one MI, $€ 0.78$ for one stroke, $€ 0.16$ for one MACE and $€ 0.20$ for one major event (CV death, MI, stroke).

With $€ 1$ annually spent per Apulia's inhabitant, 2 all-cause deaths, 3.2 MIs, 1.3 strokes and 6.1 MACEs could be avoided.

When considering subjects in secondary prevention after MI and baseline cholesterol levels $>100 \mathrm{mg} / \mathrm{dL}$, the annual cost per Apulia's inhabitant for one all-cause death avoided thanks to alirocumab therapy was more than halved to $€ 0.19$ and the cost for a saved MACE was $€ 0.09$. With $€ 1$ annually spent per Apulia's inhabitant, 10.9 MACEs and 5.3 all-cause deaths could be saved.

In an ideal scenario of treatment with evolocumab, the individual annual cost per CV event avoided thanks to PCSK9i therapy was $€ 0.13$ for one MI, $€ 0.12$ for one MACE (CV death, MI, stroke, hospitalisation for unstable 
Table 1 Overall and per inhabitant costs per saved cardiovascular events according to randomised trials and drug costs (Apulia region, South-Eastern Italy)

\begin{tabular}{|c|c|c|c|c|c|}
\hline Endpoint & ARR & NNT & $\begin{array}{l}\text { Cost per saved } \\
\text { event per year, } € \\
\text { (millions) }\end{array}$ & $\begin{array}{l}\text { Cost per saved } \\
\text { event per year per } \\
\text { inhabitant, } €\end{array}$ & $\begin{array}{l}\text { Saved events with } \\
€ 1 \text { per inhabitant per } \\
\text { year }\end{array}$ \\
\hline \multicolumn{6}{|l|}{ ODYSSEY OUTCOMES } \\
\hline All-cause death & 0.6 & 163 & 2.1 & 0.51 & 2.0 \\
\hline Ml & 1 & 100 & 1.3 & 0.31 & 3.2 \\
\hline Stroke & 0.4 & 250 & 3.2 & 0.78 & 1.3 \\
\hline MACE* & 1.9 & 53 & 0.7 & 0.16 & 6.1 \\
\hline Death, Ml, stroke & 1.6 & 64 & 0.8 & 0.20 & 5.0 \\
\hline \multicolumn{6}{|c|}{ LDL baseline levels $>100 \mathrm{mg} / \mathrm{dL}$} \\
\hline Death, Ml, stroke & 3.4 & 29 & 0.4 & 0.09 & 10.9 \\
\hline All-cause death & 1.7 & 60 & 0.8 & 0.19 & 5.3 \\
\hline \multicolumn{6}{|l|}{ FOURIER } \\
\hline $\mathrm{Ml}$ & 1.9 & 53 & 0.5 & 0.13 & 7.9 \\
\hline Stroke & 0.4 & 250 & 2.4 & 0.60 & 1.7 \\
\hline MACE† & 2 & 50 & 0.5 & 0.12 & 8.3 \\
\hline CV death, MI, stroke & 2 & 50 & 0.5 & 0.12 & 8.3 \\
\hline \multicolumn{6}{|c|}{ Multivessel coronary disease } \\
\hline MACE† & 3.6 & 28 & 0.3 & 0.07 & 15.0 \\
\hline CV death, MI, stroke & 3.4 & 29 & 0.3 & 0.07 & 14.2 \\
\hline
\end{tabular}

*Death from CV causes, non-fatal MI, unstable angina requiring hospitalisation, an ischaemia-driven coronary revascularisation procedure or non-fatal ischaemic stroke.

†Cardiovascular death, MI, stroke, hospitalisation for unstable angina, coronary revascularisation.

ARR, absolute risk reduction; CV, cardiovascular; FOURIER, Further Cardiovascular Outcomes Research with PCSK9 Inhibition in Subjects with Elevated Risk; LDL, low-density lipoprotein; MACE, major adverse CV event; MI, myocardial infarction; NNT, number needed to treat; ODYSSEY OUTCOMES, Evaluation of Cardiovascular Outcomes After an Acute Coronary Syndrome During Treatment With Alirocumab.

angina, coronary revascularisation) and $€ 0.6$ for one stroke.

With $€ 1$ annually spent per Apulia's inhabitant 7.9 MIs, 1.7 strokes and 8.3 MACEs could be avoided.

When considering subjects with multivessel coronary disease,${ }^{20}$ the annual cost per Apulia's inhabitant for one MACE avoided thanks to evolocumab therapy was near halved to $€ 0.07$. With just $€ 1$ annually spent per Apulia's inhabitant, 15 MACEs could be saved.

Costs per saved event and events saved with $€ 1$ both indexed per 1 million taxpayers are given in figure 2 for an easy application of this BIA to other taxpayers' contexts.

\section{DISCUSSION}

In this analysis we esteem for the first time possible impact of therapy with PCSK9i from a taxpayers' community perspective, simulating clinical data from two randomised studies in a public healthcare system scenario. Results show that apparently high costs per event saved, when considered from a wider perspective of a taxpayers' community, may turn into very small individual annual costs.
This approach, although not exactly 'rigorous' from a pharmacoeconomic point of view, is not completely inappropriate and disreputable. Besides cost-effectiveness analyses, BIA may more accurately assess real economic impact of new therapies and drugs on reimbursing institutions, public healthcare system administrators and taxpayers. In another drug and disease context, direct anticoagulant for the prevention of thromboembolic complications of atrial fibrillation showed that increased drug costs may be associated with lower social costs, when all the components influencing the social burden of illnesses are duly considered.$^{19}$ Higher drug costs may therefore be followed by lower social and community costs, when more expensive treatments significantly reduce adverse events and mortality rates. A health economic assessment based on a BIA rather than a cost-effectiveness analysis may be essential for a careful resource allocation when healthcare budgets should bear the burden of cuts as nowadays in several countries. As for Apulia region, annual rates of CV death is 29.7/10 000 inhabitants and 7.62/10 000 inhabitants for ischaemic heart disease. ${ }^{21}$ Given an annual incidence of acute MI of about 8000 cases ${ }^{22}$ a $30 \%$ of patients with low-density lipoprotein (LDL) levels $>100 \mathrm{mg} / \mathrm{dL}$ after acute MI 
a)

cost per saved event per year per 1 million inhabitants

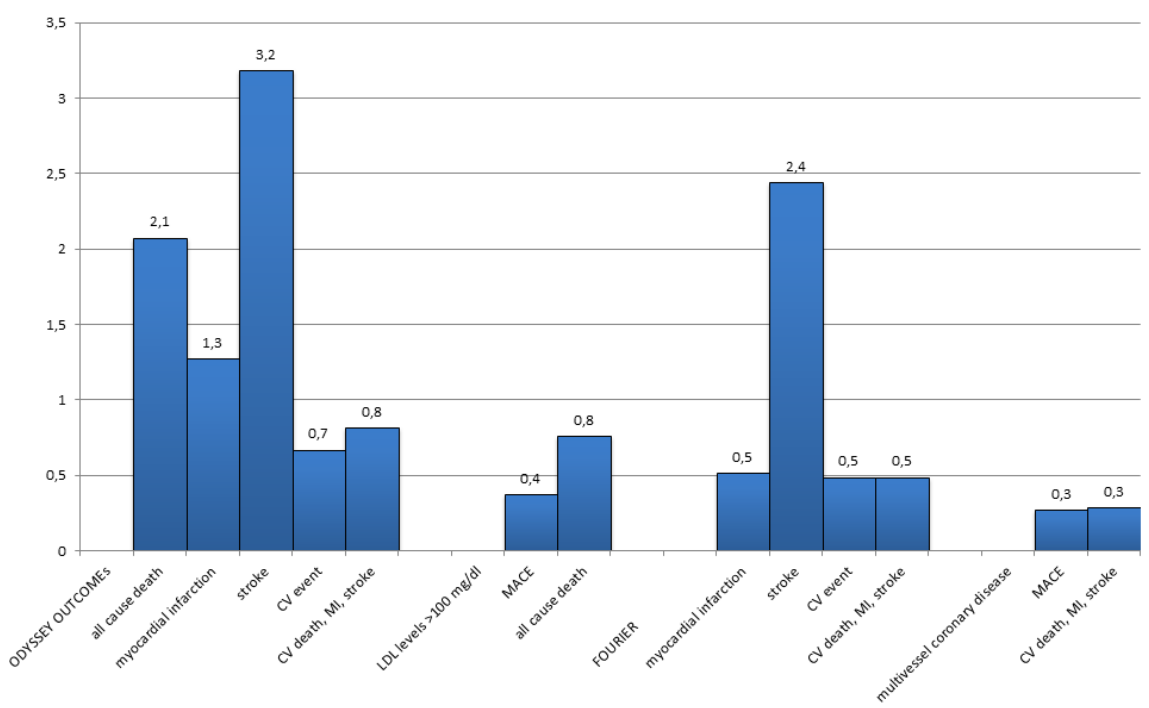

b)

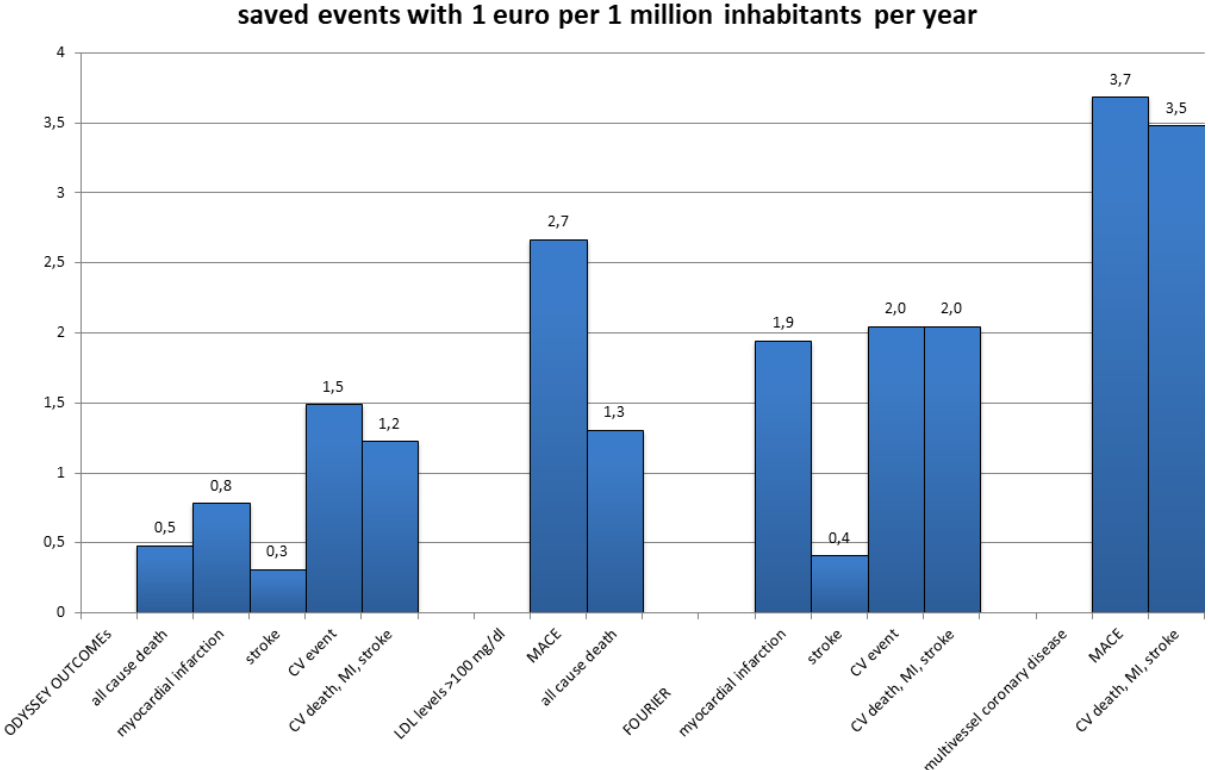

Figure 2 Indexed per 1 million taxpayers' costs per saved events $(A)$ and events saved with $€ 1$ per 1 million taxpayers (B). CV, cardiovascular; FOURIER, Further Cardiovascular Outcomes Research with PCSK9 Inhibition in Subjects with Elevated Risk; LDL, low-density lipoprotein; MACE, major adverse CV event; MI, myocardial infarction; ODYSSEY OUTCOMES, Evaluation of Cardiovascular Outcomes After an Acute Coronary Syndrome During Treatment With Alirocumab.

despite optimal therapy with statins, ${ }^{23}$ a $10 \%$ mortality rates at 1 year ${ }^{24}$ and a presumable number of reinfarctions, at least 1000-1500 patients could be hypothetically eligible for PCSK9i in Apulia every year just in secondary prevention. LDL levels $>100 \mathrm{mg} / \mathrm{dL}$ despite optimal treatment with statins and ezetimibe are currently mandatory for PCSK9i reimbursement in Apulia.

The vast majority of cost analyses available on PCSK9i, however, are still represented by cost-effectiveness evaluations based on non-clinical studies with laboratory endpoints; the recent publication of the FOURIER and the ODYSSEY OUTCOMES studies, targeted on hard clinical endpoints, allowed a series of cost-effectiveness analyses which showed contrasting conclusion on PCSK9i.
In a cost analysis from Fonarow et al, at its current (when the study was held) list price of US\$14 523, the addition of evolocumab to standard background therapy in patients with atherosclerotic CV disease exceeded generally accepted cost-effectiveness thresholds. To achieve an incremental cost-effectiveness ratio (ICER) of US $\$ 150000$ per quality-adjusted life year (QALY), the annual net price would need to be substantially lower (US\$9669 for US clinical practice and US\$6780 for trial participants), or a higher-risk population would need to be treated. ${ }^{13}$

Another updated analysis on the FOURIER data concluded that only reducing annual drug costs of evolocumab by $71 \%$ (to $\leq$ US $\$ 4215$ ) would be needed for 
PCSK9i to be cost-effective at a threshold of US\$100000/ QALY. $^{25}$

Fewer data are available when a BIA is chosen rather than cost-effectiveness analysis. In an BIA analysis from Spain, with an average annual cost of patients receiving evolocumab of $€ 11134$.78 and $€ 393.83$ for standard treatment (statins plus ezetimibe), the ICER was >€600000 per avoided CV event for both assessed outcomes (first: CV death, MI, stroke and hospitalisation due to unstable angina or coronary revascularisation; second: includes the first three events). Authors claim that treatment with evolocumab is inefficient for patients suitable to receive this drug in the Spanish National Health System. ${ }^{26}$

According to a recent study presented at 2018 American Heart Association congress, however, alirocumab was cost-effective at US $\$ 6319$ at a threshold of US\$100000 per QALY, but in patients with baseline LDL cholesterol of $100 \mathrm{mg} / \mathrm{dL}$ or greater, alirocumab was cost-effective at an even higher price of US\$13400 a year at this willingness-to-pay threshold. ${ }^{27}$

Interestingly, the actual cost per 1-year therapy with PCSK9i is in Apulia well below such esteemed cost-effectiveness threshold.

Surely, lower costs of PCSK9i would further improve the cost-effectiveness profile of this new class of drugs, but their positive impact in terms of reduced incidence of CV events is unquestioned. The identification of high-risk subgroups of patients, in the presence of clear evidence of more convenient cost-effectiveness ratios in such class of patients, may further contribute to reduce total and individual cost sustained by private and public community payers.

\section{CONCLUSIONS}

When considered from a large taxpayers' community perspective, relevant costs per CV event saved with PCSK9i may turn into very small individual costs per year. The further selection of high risk subgroups may further reduce individual costs.

\section{Limitations}

Costs per event saved are indexed for Apulia population; larger populations and taxpayers' communities may further reduce the individual costs per saved event. Lower cost of drugs may further reduce total and individual costs.

The analysis assumes for simpler calculations, a constant incidence of events during follow-up and a 'global' population of taxpayers; results may be therefore reassessed and corrected according to the ratio of taxpayers over local population ( $50 \%$ taxpayers, double costs ...).

Contributors PC conducted the study, LT gathered data, NDB analysed data, LDG and NDB wrote the paper, and PC and NDB supervised the study.

Funding The authors have not declared a specific grant for this research from any funding agency in the public, commercial or not-for-profit sectors.

Competing interests NDB received honoraria from Sanofi as consultant.

Patient consent for publication Not required.
Provenance and peer review Not commissioned; externally peer reviewed.

Data availability statement There are no additional data available in this work.

Open access This is an open access article distributed in accordance with the Creative Commons Attribution Non Commercial (CC BY-NC 4.0) license, which permits others to distribute, remix, adapt, build upon this work non-commercially, and license their derivative works on different terms, provided the original work is properly cited, appropriate credit is given, any changes made indicated, and the use is non-commercial. See: http://creativecommons.org/licenses/by-nc/4.0/.

\section{REFERENCES}

1. Nissen SE, Stroes E, Dent-Acosta RE, et al. Efficacy and tolerability of evolocumab vs ezetimibe in patients with muscle-related statin intolerance: the GAUSS-3 randomized clinical trial. JAMA 2016;315:1580-90.

2. Koren MJ, Lundqvist P, Bolognese M, et al. Anti-PCSK9 monotherapy for hypercholesterolemia: the MENDEL-2 randomized, controlled phase III clinical trial of evolocumab. J Am Coll Cardiol 2014;63:2531-40.

3. Cannon CP, Cariou B, Blom D, et al. Efficacy and safety of alirocumab in high cardiovascular risk patients with inadequately controlled hypercholesterolaemia on maximally tolerated doses of statins: the odyssey Combo II randomized controlled trial. Eur Heart J 2015;36:1186-94.

4. Giugliano RP, Keech A, Murphy SA, et al. Clinical efficacy and safety of evolocumab in high-risk patients receiving a statin: secondary analysis of patients with low LDL cholesterol levels and in those already receiving a Maximal-Potency statin in a randomized clinical trial. JAMA Cardiol 2017:2:1385-91.

5. Kastelein JJP, Ginsberg HN, Langslet G, et al. Odyssey FH I and FH II: 78 week results with alirocumab treatment in 735 patients with heterozygous familial hypercholesterolaemia. Eur Heart $J$ 2015;36:ehv370-3.

6. Farnier M, Jones P, Severance R, et al. Efficacy and safety of adding alirocumab to rosuvastatin versus adding ezetimibe or doubling the rosuvastatin dose in high cardiovascular-risk patients: the odyssey options II randomized trial. Atherosclerosis 2016;244:138-46.

7. Markham A. Evolocumab: first global approval. Drugs 2015;75:1567-73.

8. Karatasakis A, Danek BA, Karacsonyi J, et al. Effect of PCSK9 inhibitors on clinical outcomes in patients with hypercholesterolemia: a meta-analysis of 35 randomized controlled trials. J Am Heart Assoc 2017;6. doi:10.1161/JAHA.117.006910].

9. Robinson JG, Nedergaard BS, Rogers WJ, et al. Effect of evolocumab or ezetimibe added to moderate- or high-intensity statin therapy on LDL-C lowering in patients with hypercholesterolemia: the LAPLACE-2 randomized clinical trial. JAMA 2014;311:1870-82.

10. Sabatine MS, Giugliano RP, Keech AC, et al. Evolocumab and clinical outcomes in patients with cardiovascular disease. $N$ Engl $J$ Med 2017;376:1713-22.

11. Schwartz GG, Steg PG, Szarek M, et al. Alirocumab and cardiovascular outcomes after acute coronary syndrome. $N$ Engl J Med 2018;379:2097-107.

12. Grundy SM, Stone NJ, Bailey AL, et al. 2018 AHA/ACC/AACVPR/ AAPA/ABC/ACPM/ADA/AGS/APhA/ASPC/NLA/PCNA guideline on the management of blood cholesterol: executive summary: a report of the american college of cardiology/american heart association task force on clinical practice guidelines. J Am Coll Cardiol 2019;73:3168-209.

13. Fonarow GC, Keech AC, Pedersen TR, et al. Cost-Effectiveness of evolocumab therapy for reducing cardiovascular events in patients with atherosclerotic cardiovascular disease. JAMA Cardiol 2017;2:1069-78.

14. Gandra SR, Villa G, Fonarow GC, et al. Cost-Effectiveness of LDL-C lowering with evolocumab in patients with high cardiovascular risk in the United States. Clin Cardiol 2016;39:313-20.

15. Virani SS, Akeroyd JM, Nambi V, et al. Applicability and cost implications for proprotein convertase subtilisin/kexin type 9 inhibitors based on the odyssey outcomes trial. Circulation 2019;139:410-2.

16. Poulsen PB, Johnsen SP, Hansen ML, et al. Setting priorities in the health care sector - the case of oral anticoagulants in nonvalvular atrial fibrillation in Denmark. Clinicoecon Outcomes Res 2017;9:617-27

17. Garattini L, van de Vooren K. Budget impact analysis in economic evaluation: a proposal for a clearer definition. Eur J Health Econ 2011;12:499-502.

18. Apulia. Available: https://en.wikipedia.org/wiki/Apulia [Accessed 8 Dec 2018]. 
19. Brunetti ND, De Gennaro L, Caldarola P, et al. Direct oral anticoagulants for the prevention of thromboembolic complications of atrial fibrillation: the more you pay, the less you spend? Int $J$ Cardiol 2017;241:238-40.

20. Sabatine MS, De Ferrari GM, Giugliano RP, et al. Clinical benefit of evolocumab by severity and extent of coronary artery disease. Circulation 2018;138:756-66.

21. I.Stat. Initial cause of death - European Short List, 2019. Available: http://dati.istat.it/Index.aspx?DataSetCode=DCIS_CMORTE1_RES\# [Accessed 24 Jun 2019].

22. Concept paper sul Progetto inibitori di PCSK9: accesso E sostenibilit. SPS N. 1, 2019Available: https://issuu.com/pensiero/ docs/supp_ps_1-2019_web [Accessed 24 Jun 2019].

23. De Luca L, Temporelli PL, Lucci D, et al. Characteristics, treatment and quality of life of stable coronary artery disease patients with or without angina: insights from the start study. PLoS One 2018;13:e0199770.
24. Ministry of Health, National Agency for Regional Health Services. Infarto Miocardico Acuto: mortalit a un anno, 2019. Available: https:// pne.agenas.it/PNEed17/risultati/tipo1/intr_struasl1_HC.php?ind=88\& tipo $=1 \&$ area $=1$ [Accessed 25 Jun 2019].

25. Kazi DS, Penko J, Coxson PG, et al. Updated cost-effectiveness analysis of PCSK9 inhibitors based on the results of the Fourier trial. JAMA 2017;318:748-50.

26. Olry de Labry Lima A, Gimeno Ballester V, Sierra Sánchez JF, et al. Cost-Effectiveness and budget impact of treatment with evolocumab versus statins and ezetimibe for hypercholesterolemia in Spain. Rev Esp Cardiol 2018;71:1027-35.

27. 19490 - Cost-effectiveness of alirocumab based on evidence from a large multinational outcome trial: The odyssey outcomes economics study. Available: http://www.abstractsonline.com/pp8/\#!/4682/ presentation $/ 59408$ 